\title{
50 anos do GEL: caminhos da linguística no Brasil
}

DOI: http://dx.doi.org/10.21165/el.v49i1.2508

\section{Olga Ferreira Coelho'}

\section{Resumo}

Neste artigo, são analisados 4108 artigos publicados nas revistas do GEL entre 1993 e 2018, com o objetivo de oferecer um perfil da produção linguística em circulação no Grupo. Além disso, se apresenta um conjunto de propostas para o futuro do GEL. O perfil e as propostas foram elaborados em consonância com princípios da Historiografia Linguística.

Palavras-chave: 50 anos do GEL; Historiografia Linguística; linguística brasileira.

1 Universidade de São Paulo (USP), São Paulo, São Paulo, Brasil; olgafc@usp.br; https://orcid.org/0000-0002-3688-5627. 


\title{
The $\mathbf{5 0}^{\text {th }}$ GEL's anniversary: paths of linguistics in Brazil
}

\author{
Abstract \\ In this paper, 4108 articles published by GEL' journals between 1993 and 2018 were \\ analyzed under the aim of mapping up trends in Linguistic research at GEL's context. \\ Besides that, it reports a set of suggestions for the Group's future. Profile and suggestions \\ were assessed according to the principles of Linguistic Historiography.
}

Keywords: The $50^{\text {th }}$ GEL's anniversary; Linguistic Historiography; Brazilian linguistics.

\section{A historiografia linguística em tempos de negacionismo histórico}

Parte da bibliografia introdutória à Historiografia Linguística foi dedicada a reforçar a ideia de que a escrita da história é um fazer interpretativo (cf., entre outros, KOERNER, 2014; SWIGGERS, 2005 [2004], 2013; COELHO; HACKEROTT, 2012). Muitos dos que já se ocuparam de definir ou caracterizar o campo de estudos, seus objetos e métodos, desde pelo menos os anos 1970, ressaltaram que a pesquisa na área resulta de uma série de escolhas, de hierarquizações e de projeções inevitavelmente efetuadas na história dos estudos da linguagem pelos historiógrafos. É, assim, ponto pacífico que a pesquisa historiográfica leva à elaboração de uma versão parcial de uma parte da história, e que a consistência descritivo-interpretativa dessa versão depende, pelo menos, de apoio documental e de apoio explícito em um conjunto de referências teóricas e metodológicas aceitas (ou aceitáveis), porque têm sido elaboradas, discutidas, aplicadas, explicadas, criticadas, replicadas, difundidas no "campo" (cf. BOURDIEU, 2004). Essa visão permite ter tranquilidade, por exemplo, para escolher temas, períodos, atores, contextos, problemas (linguísticos, científicos, institucionais) a cuja história se dê ênfase; permite selecionar, analisar, correlacionar, interpretar aspectos diversificados para o entendimento do "caso" em estudo, e, ainda, tratá-los de modos às vezes peculiares, mas sempre ancorados em consensos mínimos de razoabilidade, construídos por gerações de historiadores e historiógrafos. Admite-se, portanto, que os chamados "fatos" históricos têm ampla dimensão interpretativa e que os resultados a que se chega por meio da pesquisa historiográfica necessariamente são subjetivos, incompletos ou, para usar um termo da moda, "ideológicos".

Mas é preciso frisar, mesmo nesta segunda década do século XXI, que há um substrato no qual o trabalho interpretativo do historiógrafo se apoia, composto, no mínimo, por certa familiaridade com noções e práticas características do "campo", exame acurado da documentação relevante disponível, definição e explicitação de pressupostos e métodos (válidos) para a pesquisa histórica. 
Após anos de desenvolvimento dos estudos da linguagem e, em especial, dos estudos do texto e do discurso - tão difundidos no Brasil -, parecia já desnecessário chamar atenção para o sentido em que se pode dizer que a Historiografia produz interpretações do seu objeto, a história dos estudos da linguagem e das línguas. Entretanto, neste momento, no Brasil, os historiadores que lidam com a história social e política têm sido, por exemplo, desafiados a reafirmar, com base na documentação disponível e em métodos e teorias de trabalho com histórias aceitáveis nos nossos dias, que houve ditadura no país, que houve (e há) tortura, que houve crimes de estado que exigem reparação, que foram das mais torpes as formas de escravização africana por aqui, que o racismo, o machismo, a homofobia vêm sendo perpetuados em nossas vivências sociais etc., etc. Nenhuma (re-) interpretação, nenhuma revisão histórica séria permite negar isso. Na mesma medida, tem sido necessário que o historiógrafo da linguística e os linguistas reafirmem que a reflexão e o tratamento da linguagem e das línguas estiveram (e estão) na base do desenvolvimento do pensamento crítico no ocidente, que esses estudos estiveram (e estão) na base do desenvolvimento de técnicas e tecnologias tão variadas (e "úteis") quanto as psicanalíticas, educacionais e as computacionais, por exemplo. Tem sido necessário lembrar à academia, aos professores e aos estudantes o valor das iniciativas coletivas, a força que pode advir do esforço de cooperar, de atuar junto.

Foi dessa vontade de reafirmação da relevância e pujança dos estudos da linguagem no Brasil que se desenvolveu a pesquisa reportada neste artigo $^{2}$. Apresentam-se alguns resultados de um projeto amplo de releitura da história "interna" e "externa" do GEL. O projeto visou à difusão de uma versão dessa história em mídias principalmente eletrônicas, para atingir o maior número de pessoas possível, principalmente os estudantes de Letras e Linguística, que precisam se reencontrar com a própria história e apropriar-se dela seja para afırmação social no presente, seja para planejamento do futuro.

Para uma releitura da história do GEL em seus 50 anos, foram feitas as seguintes escolhas:

\footnotetext{
2 Uma série de cooperações tornou possível a realização da pesquisa que fundamenta este artigo e a criação de um site, um e-book e um caderno comemorativo do cinquentenário do Grupo de Estudos Linguísticos do Estado de São Paulo (GEL). Ao longo de um ano de trabalho, vimos mostras de um forte apreço pelo Grupo e de crença nas construções (intelectuais e sociais) coletivas. É preciso, então, agradecer pela participação ou pelo apoio à iniciativa: aos ex-presidentes do GEL, a Luciani Tenani, Ênio Sugiyama Jr., Rogério Nóbrega, Bruno Fochesato, Maryellen Cruz, Isadora Vaz, Karina Oliveira, Renata Sbroggio, Fabiana Komesu, Lílian Maria da Silva, Rômulo Borim, Marcelo Módolo, Waldemar Ferreira Neto, Ataliba de Castilho, Roberto Gomes Camacho, CEDAE-UNICAMP, CEDOCH-DL-USP, Programa de Pós-Graduação em Estudos Linguísticos do IBILCE, Departamento de Linguística da USP e seu Programa de Pós-Graduação, Diretoria do GEL (biênio 2017-2019), CAPES, Pró-Reitorias de Pesquisa e Extensão da USP, Programa Unificado de Bolsas da USP.
} 
- exame de documentação disponível no Acervo GEL do CEDAE-UNICAMP (atas, documentos dos seminários, correspondências, documentação legal, fichas de associados, imagens, revisões históricas anteriores);

- realização de entrevistas com 23 membros das 25 diretorias do GEL, nas quais se perguntou: 1) O que significava o GEL para a Linguística de São Paulo e do Brasil no momento em que você participou de sua diretoria? Houve algum fato marcante ou curiosidade que gostaria de partilhar? e 2) Que papel o GEL poderia desempenhar hoje, diante dos desafios que você vislumbra para a Linguística (brasileira) contemporânea?;

- realização de entrevista com coordenadores de programas de pós-graduação em linguística das universidades públicas paulistas, com as perguntas: 1) Que papel o GEL poderia desempenhar hoje, diante dos desafios que você enxerga para a Linguística (brasileira) contemporânea? e 2) Que ações poderiam ser implantadas pelo GEL?;

- exame dos artigos publicados na Estudos Linguísticos (São Paulo. 1978) e na Revista do $G E L$, segundo critérios "externos" (data, volume, organizadores, autoria, instituições, nível de treinamento dos autores) e "internos" (tipo de texto, título, objeto, orientação, nível de descrição, auto-vinculação teórica ou disciplinar).

Essas escolhas permitiram lidar com fontes variadas, o que possibilitou, por sua vez, a checagem de informações em mais de uma delas. Tal variação também levou a que os resultados da pesquisa fossem diversificados: 1 site (TENANI et al., 2018); uma cronologia impressa no Caderno Comemorativo dos 50 anos do GEL (COELHO et al., 2019); 1 e-book com uma história "externa" do GEL e este artigo, que dá ênfase à história interna, isto é, à produção linguística do GEL, sobretudo nos últimos 25 anos (1993-2018).

\section{Os $\mathbf{5 0}$ anos do GEL e a institucionalização da linguística no Brasil}

A história do GEL coincide, em muitos aspectos, com a história da linguística no Brasil. 0 GEL e a ABRALIN (Associação Brasileira de Linguística) foram fundados no mesmo ano, 1969, ambos, aparentemente, com certo protagonismo do professor Ataliba Teixeira de Castilho, que, a partir de Marília, procurou convencer tanto a um grupo de linguistas em início de carreira, quanto a alguns filólogos do período, como Isaac Nicolau Salum (19131993), da relevância desses fóruns coletivos para o fortalecimento da área de estudos da linguagem (cf., a esse respeito, ALTMAN, 2004, 2018; COELHO et al., 2019). O GEL já inicia suas atividades nesse mesmo ano da fundação, com a proposta de realizar os seminários em faculdades do interior do estado de São Paulo, para que os linguistas que estudaram na USP e depois no exterior pudessem, primeiro, afinar um pouco seus pressupostos e métodos, e, segundo, difundir as novas orientações, com que tinham tido contato, entre colegas e alunos dos cursos de Letras do interior. Havia também, evidentemente, os objetivos de dar visibilidade, de conseguir recursos para o trabalho, de lastrear a linguística 
como uma especialidade no Brasil. Os primeiros encontros têm poucos participantes, quando muitos, contados às dezenas. Mas a área se expande consideravelmente a partir dos anos 1990, e o GEL acompanha esse movimento, promovendo 67 seminários ao longo de seus 50 anos, com uma quantidade de participantes que facilmente tem superado um milhar.

Em 1995, Altman et al. analisaram as comunicações publicadas nos então chamados Estudos Linguísticos: Anais de seminários do GEL. Naquela ocasião, foram identificados certos caminhos percorridos pela linguística no âmbito deste Grupo. Por exemplo, comprovou-se uma franca preferência pelo estudo do português (mais de 83\% das comunicações publicadas), em contraste com a quase ausência de exames de dados de línguas indígenas (cerca de 4\%). Também se verificou, em 1995, um deslocamento da "incidência" dos trabalhos que analisavam dados de línguas: em um primeiro momento (1974-1984), deu-se maior atenção aos domínios da palavra e da sentença, para, em momento posterior (1985-1992), as atenções se voltarem preponderantemente para os textos e discursos.

A nova análise, feita em 4.108 artigos publicados entre 1993 e 2018 nos dois periódicos do GEL, reafirmou, em linhas gerais, esses caminhos, mas apontou também novas possibilidades, em construção entre linguistas brasileiros que publicam nas revistas do Grupo.

Neste artigo, são apresentadas sínteses preliminares da nova análise, concentradas na Estudos Linguísticos (São Paulo. 1978), e, em seguida, um apanhado de aspirações e propostas de ex-presidentes do GEL e de atuais coordenadores de programas de pósgraduação em linguística de universidades públicas de São Paulo, encontradas no corpus de entrevistas publicadas no site comemorativo dos 50 anos do GEL. A ideia é que, com elementos advindos da comunidade do GEL (o que ela tem feito e o que ela julga necessário fazer), seja possível refletir sobre os seus próximos anos.

\section{A produção linguística publicada pelo GEL nos últimos 25 anos}

Este mapeamento corresponde a uma primeira abordagem de alguns dos traços de um mapa mais amplo. Pode-se considerá-lo como um primeiro esboço, de apenas alguns dos pontos relevantes dessa produção.

À primeira vista, parece que esses pontos são uma materialização muito ilustrativa de características intuitivamente perceptíveis na área. 


\subsection{Expansão da área e aceleração do ritmo de trabalho}

É clara para todos a expansão da área de Letras e Linguística, marcada pela multiplicação de cursos de graduação e de programas de pós-graduação (em 2016, dados do MEC apontavam 475 cursos presenciais de graduação em Letras, 35 programas de pósgraduação em Linguística e 122 programas de pós-graduação em Letras).

Ao lado dessa expansão, também se reconhece intuitivamentea aceleração dos processos de produção e publicação de textos na área, relacionada a sistemas de avaliação que ainda têm dado muita atenção à quantidade de produtos publicados.

Assim, a primeira observação a ser feita é que os periódicos do GEL exemplificam bem a expansão da área e a aceleração no ritmo de trabalho e de publicação, muito provavelmente acompanhada de algum decréscimo qualitativo da produção, embora os dados desta pesquisa não permitam afirmar isso.

Veja-se, como ilustração, esta tabela que compara dados relativos à publicação no GEL entre 1978 e 1992, de um lado, e 1993-2018, de outro lado:

Tabela 1. Produção publicada nos 50 anos do GEL

\begin{tabular}{l|l|l}
\hline PUBLICAÇÕES & 1 & 2 \\
\hline VOLUMES & 22 & 85 \\
\hline NÚMERO DE TEXTOS & 845 & 4.108 \\
\hline NÚMERO DE PÁGINAS & 9.249 & 37.497 \\
\hline
\end{tabular}

Fonte: Elaboração própria

Tem havido publicação ininterrupta dos dois periódicos do GEL desde a fundação de cada um deles, a Estudos Linguísticos (São Paulo. 1978) (EL), em 1978, e a Revista do GEL (RGEL), em 2002.

A tabela mostra que, no primeiro período, o GEL tinha apenas um veículo para publicação de trabalhos e passou a ter dois no segundo intervalo temporal. Foram publicados, nos últimos 25 anos, nada menos que 30 volumes RGEL e 55 volumes EL e a quantidade de textos, na mesma extensão temporal de 25 anos, mais que triplicou. 
O pico desse processo está no começo dos anos 2000, quando são publicadas centenas de textos de 5-6 páginas nos Estudos Linguísticos. Há volumes com mais de mil páginas, alguns com mais de 300 textos (em 2003, por exemplo, foram publicados 343 artigos).

Paulatinamente foi havendo uma recomposição daquele cenário, mais marcadamente a partir de 2007, com a implementação de políticas de seleção e de qualificação da EL, acompanhando, outra vez, uma política mais geral de busca de parâmetros qualitativos de avaliação da produção na área de Letras e Linguística.

A média, a partir de 2007, tem girado em torno de 100 textos publicados por ano. Em 2018, foram 59 os selecionados.

\subsection{Instituições presentes nas publicações do GEL}

Um mapeamento das instituições a que se vincularam os autores dos artigos publicados pela EL mostrou que: 80 dessas instituições eram do estado de São Paulo, 101, de outros estados brasileiros e 16 do exterior. Além disso, 76 autores sem vínculos institucionais publicaram na $E L$.

Entre os autores vinculados a instituições estrangeiras, todos eram participantes convidados, com exceção de um pesquisador da Universidade de Abidjan, na Costa do Marfim.

Nem todos os autores vinculados a instituições estavam em cursos de Letras. Há muitos outros cursos mencionados e há instituições não voltadas para ensino (como IML, EMBRAPA), indicando interesses interdisciplinares mútuos.

Foram mapeadas 197 instituições diferentes, o que indica a existência de uma ampla rede de interessados em Letras e Linguística, ou em diálogo com essa área no Brasil.

Uma outra síntese possível a partir desses dados é a de que o GEL não é mais uma associação apenas paulista. A participação de linguistas de todo o Brasil nos seminários e nas publicações é constante e quantitativamente significativa. No seminário de 2018, por exemplo, segundo o relatório da diretoria do GEL para a FAPESP, 1/3 dos participantes vinha de outros estados brasileiros.

Cruzando esse levantamento com a quantidade de textos, observamos que há uma presença maior da produção das 3 universidades estaduais paulistas ( $57 \%$ do total). 
Fora deste eixo, aparece primeiramente um conjunto de outras universidades públicas.

Cerca de 700 textos separam a produção publicada da UNESP daquela da primeira instituição particular a aparecer neste recorte.

A universidade pública é a responsável pela maioria dos textos veiculados.

\subsection{Objetos estudados}

Os objetos analisados nos textos foram categorizados, neste mapeamento, em Línguas $(\mathrm{L}, 72 \%)$, Questões teóricas relativas a línguas e linguagens ( $\mathrm{T}, 22 \%)$ e Outros objetos $(0,6 \%)$.

Em relação aos textos alocados em $L$, nota-se que dados de várias línguas, do Brasil e do Mundo, em seus diferentes estágios históricos e em suas diferentes variedades, estão contemplados. Chama ainda a atenção, assim como havia chamado 25 anos atrás, a concentração no português: ele é o foco de cerca de $80 \%$ dos textos que exploram dados de língua (2200 de 2755). As línguas indígenas brasileiras ainda representam 3,6\% das estudadas, também não alterando sua presença como objeto de descrição e análise linguística de 25 anos atrás.

É relativamente pequena a quantidade de textos do tipo T (22\% do total). Ela aparece principalmente em textos que apresentam novas disciplinas ou novos objetos, instituídos sobretudo a partir dos anos 1990 no contexto brasileiro (tais como a Análise da Conversação, Linguística de Corpus, a Historiografia Linguística, a Análise Crítica do Discurso, a Linguística Computacional, a Linguística Cognitiva, a Morfologia Distribuída, a Pragmática formal, entre outras). Sua emergência ensejou textos sobre as disciplinas, seus objetos, métodos, relações interdisciplinares, revisões históricas e epistemológicas, discussão de seus modos de institucionalização etc..

Há uma proporção considerável desses trabalhos reconhecidos como T que aborda dados e processos linguísticos com finalidade teórica. O foco, nesse caso, é a discussão teórica, exemplificada, ilustrada, com determinados dados. Não encontramos neste corpus particular da EL a articulação de modelos teóricos "originais".

Em O, há sobretudo análises de linguagens não verbais a partir do aparato da Semiótica, mas também objetos como formação de professor e técnicas de ensino de língua materna e estrangeira. 


\subsection{A fênix renasceu}

Outro fator observado foi a orientação (sincrônica ou diacrônica) dos textos. A análise mostra que, embora preponderem os estudos chamados sincrônicos, a presença da orientação diacrônica aumentou significativamente: de menos de $2 \%$ dos trabalhos sobre o português nos primeiros 25 anos, chegam a 12\% do total de trabalhos publicados nestes últimos 25 anos. Ou seja, prepondera a abordagem sincrônica, mas é mais comum do que nos períodos de franca prevalência do Estruturalismo e do Gerativismo no Brasil o olhar para a diacronia e mesmo um trânsito entre as duas perspectivas.

\subsection{Unidades linguísticas selecionadas para as análises}

Observou-se também o tipo de unidade linguística enfatizada em cada trabalho do tipo L e em alguns do tipo T (os que remetiam a questões linguísticas explícitas).

Muitos dos trabalhos estabelecem claramente um tipo de unidade a ser tratada. Mas tem sido bastante comum, desde os anos 1990, o trânsito por alguns dos chamados níveis de articulação e análise linguística, e até mesmo por todos, em abordagens apresentadas como mais integrativas. Quando houve esse trânsito, mas houve ênfase, optamos por classificar o texto segundo a unidade mais claramente privilegiada nos trabalhos. Quando não foi possível enxergar hierarquização, ou quando os objetos não eram L, usamos "não se aplica".

A análise mostra plena hegemonia dos trabalhos que tratam de texto e discurso, e uma acentuação significativa dessa preponderância nestes últimos 25 anos: nos primeiros 25 , tínhamos $31 \%$ dos trabalhos tratando de texto e discurso. Agora são $58 \%$ do conjunto total de artigos publicados. Em sequência decrescente, a distribuição é de: 16\% de análise lexical; 12\%, morfossintática; 9\%, semântico-pragmática e 5\%, fonético-fonológica.

Há atualmente na EL uma distribuição um pouco mais homogênea dos textos em relação a este critério, talvez induzida, ao menos em parte, por uma nova política editorial da revista, que, por exemplo, fixou seções dedicadas aos diferentes objetos, reduziu a quantidade total de artigos publicados e parece buscar um certo equilíbrio em relação à distribuição quantitativa dos trabalhos selecionados para publicação em cada seção.

\subsection{Um emaranhado de referências teórico-metodológicas}

Outro aspecto analisado nos artigos foi sua "Autovinculação teórica ou disciplinar", que, grosso modo, diz respeito a que teorias, correntes, escolas ou até mesmo disciplinas os autores vincularam seus trabalhos. 
Não foi possível ainda articular uma primeira descrição quantitativa dessa categoria, que é muito multifacetada. Há múltiplas vinculações, o que não é exatamente problema em face da natureza heterogênea da linguagem, que requer mesmo vários olhares. É também comum a ausência de menção desse aspecto nos textos, sobretudo nos anteriores aos anos 2000 .

Em vista dessas coerções, essa dimensão dos artigos só pôde ser analisada de uma forma um pouco mais genérica, a partir da elaboração de uma nuvem de palavras lexicais que apareceram nas variadas autovinculações mencionadas nos textos.

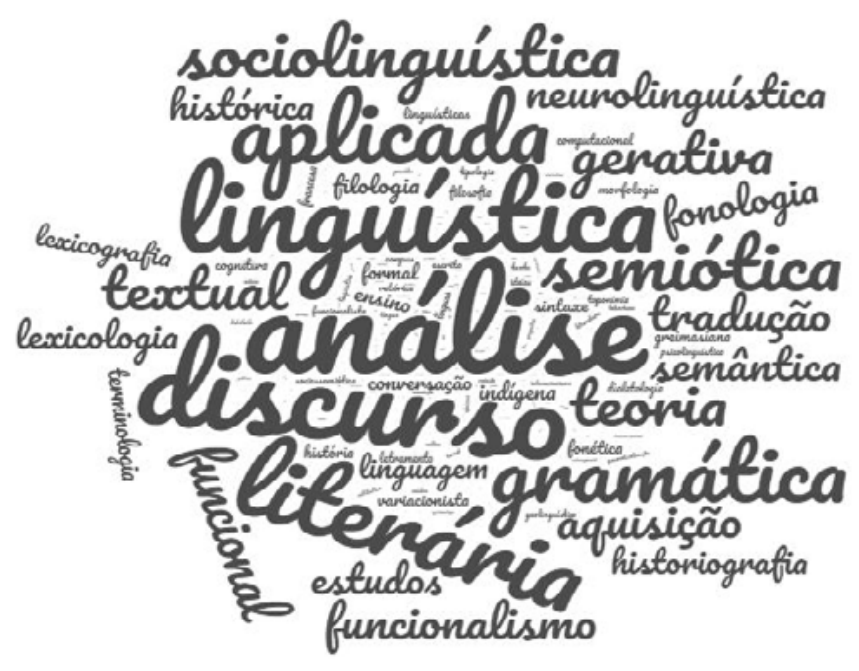

Figura 1. Nuvem de palavras lexicais das autovinculações explicitadas nos artigos da $E L$

Fonte: Elaboração de Karina Oliveira, doutoranda do CEDOCH-DL-USP

Essa nuvem permite ter uma ideia indireta de proporcionalidade entre os modelos teóricometodológicos em circulação no GEL nos últimos 25 anos.

\section{Propostas para o futuro do GEL}

Para elaborar a lista de propostas que se segue, utilizou-se um conjunto de respostas confluentes para esta pergunta proposta na entrevista aos presidentes e coordenadores: Que papel o GEL poderia desempenhar hoje, diante dos desafios que você vislumbra para a Linguística (brasileira) contemporânea? 


\section{(01) Sugestões para a atuação futura do GEL}

- Promover inter e multidisciplinaridade;

- Fomentar o intercâmbio acadêmico-cientifico nacional;

- Incrementar formas de divulgação dos resultados da pesquisa junto à sociedade;

- Promover a discussão de modelos qualitativos de avaliação inter e intrainstitucionais, sobretudo na pós-graduação;

- Proporcionar a criação de fóruns que permitam desenvolver teorias, começando com a organização de um pós-doutorado interinstitucional;

- Auxiliar na articulação e no desenvolvimento de grupos de pesquisa e de pesquisas em grupo;

- Discutir processos de internacionalização em curso no Brasil e seu impacto nos modos de existência do PB e da literatura e da cultura brasileiras nesse contexto;

- Atentar-se para novas tendências no campo científico, como a ênfase em abordagens empíricas;

- Atentar-se para novas formas de configuração dos objetos de interesse da Linguística (novas tecnologias, novas formas de comunicação, novos arranjos no campo social), que trazem impacto à pesquisa e à configuração de disciplinas que se ocupam dos usos linguísticos;

- Contribuir para demonstrar a relevância social e acadêmica dos estudos da linguagem e das ciências humanas de uma forma geral;

- Manter-se como um fórum de debates de políticas públicas, sobretudo as relacionadas à educação;

- Engajar-se em movimentos que visam à popularização e divulgação do conhecimento produzido na universidade;

- Reagir a ataques políticos às humanidades.

Parecem muito oportunas e urgentes essas ações, principalmente aquelas que apontam para uma atuação mais forte do GEL no contexto social, político, educacional e científico brasileiro atual. 
Urge também reafirmar as especificidades e o inestimável valor dos estudos da linguagem para a compreensão do Homem e da Sociedade.

Neste sentido, este capítulo particular da história dos estudos da linguagem no Brasil, o da fundação e desenvolvimento sólido de uma associação de professores e estudantes - que insiste na preservação de um ambiente democrático e acolhedor para os mais diferentes perfis de pesquisadores e de pesquisas -, pode ajudar a inspirar, também em outros âmbitos, a convivência democrática em meio à diversidade, a priorização das instâncias de representação e de congregação dos atores sociais, a conjunção entre memória e planejamento para a construção do presente e do futuro.

Parafraseando o depoimento de Roberto Gomes Camacho ao site comemorativo dos 50 anos do GEL (TENANI et al., 2018), nossa história nos faz relembrar de que as humanidades e as ciências da linguagem têm um papel central no cenário científico, social e político, entre outras razões, porque somente elas permitem identificar, denunciar e desconstruir a mentira, a ignorância, o fanatismo, o cinismo, o autoritarismo, enfım, toda esta sorte de ilegitimidades que têm vigorado do Brasil.

\section{REFERÊNCIAS}

ALTMAN, C. et al. Mapeamento historiográfico de produção linguística nos 25 anos do GEL. Estudos Linguísticos, Anais de seminários do GEL, Franca, p. 50-57, 1995. Disponível em: https://bit.ly/3cvbHZ1. Acesso em: 31 ago. 2019.

ALTMAN, C. et al. A pesquisa linguística no Brasil (1968-1988). 2. ed. São Paulo: Humanitas, 2004.

ALTMAN, C. et al. Filologia e linguística brasileiras, mais uma vez. In: COELHO, O. F. (org.). A historiografia Linguística no Brasil (1993-2018): Memória, estudos. Campinas: Pontes, 2018. p. 43-64.

BOURDIEU, P. Os usos sociais da ciência. Por uma sociologia clínica do campo científico. São Paulo: Unesp/INRA, 2004.

CAMACHO, R. G. Depoimento. Seção Memórias. In: TENANI, L. et al. GEL: 50 anos. [Site comemorativo dos 50 anos do Grupo de Estudos Linguísticos do Estado de São Paulo]. São José do Rio Preto: IBILCE-UNESP, 2018. https://www.gel.org.br/50anos/. Acesso em: 31 ago. 2019. 
CEDAE (CENTRO DE DOCUMENTAÇÃO ALEXANDRE EULÁLIO - UNICAMP). Disponível em: http://www3.iel.unicamp.br/cedae/. Acesso em: 31 ago. 2019.

CEDOCH (CENTRO DE DOCUMENTAÇÃO EM HISTORIOGRAFIA DA LINGUÍSTICA DO DEPARTAMENTO DE LINGUÍSTICA DA USP). Disponível em: http://www.cedoch.fflch.usp. br/. Acesso em: 31 ago. 2019.

COELHO, O. F.; HACKEROTT, M. M. S. Historiografia Linguística. In: GONÇALVES, A. V.; GÓIS, M. L. S. (org.). Ciências da linguagem: o fazer científico? Campinas: Mercado de Letras, 2012. p. 381-407.

COELHO, O. F. et al. Caderno Comemorativo dos 50 anos do GEL. São José do Rio Preto: GEL, 2019.

COELHO, O. F. et al. 50 Coisas para saber sobre o GEL. São José do Rio Preto: Programa de Pós-graduação em Estudos Linguísticos do IBILCE-UNESP, GEL. Araraquara: Letraria, 2019 .

ESTUDOS LINGUÍSTICOS. https://revistas.gel.org.br/estudos-linguisticos. Acesso em: 31 ago. 2019.

GEL (Grupo de Estudos Linguísticos do Estado de São Paulo). https://www.gel.org. br/50anos/?p=1. Acesso em: 31 ago. 2019.

KOERNER, K. Quatro décadas de historiografia linguística: estudos selecionados. [Coleção Linguística 11, prefácio de Carlos Assunção, seleção e edição de textos de Rolf Kemmler e Cristina Altman]. Vila Real: Universidade de Trás-os-Montes e Alto Douro, Centro de Estudos em Letras. 2014..

REVISTA DO GEL. São Paulo. Disponível em: https://revistas.gel.org.br/rg. Acesso em: 31 ago. 2019.

TENANI, L. et al. GEL: 50 anos. [Site comemorativo dos 50 anos do Grupo de Estudos Linguísticos do Estado de São Paulo]. São José do Rio Preto: IBILCE-UNESP, 2018. Disponíve em: https://www.gel.org.br/50anos/. Acesso em: 31 ago. 2019.

TENANI, L. et al. Relatório científico do $66^{\circ}$. Seminário do GEL [Entregue à FAPESP]. São José do Rio Preto: IBILCE-UNESP, 2018. 
SWIGGERS, P. A historiografia linguística. Objeto, objetivos, organização. Revista Confluência, Rio de Janeiro, Liceu Literário Português, n. 44-45, p. 39-59, 2013.

SWIGGERS, P. Modelos, métodos y problemas en la historiografía de la lingüística. Nuevas aportaciones a la historiografía lingüística. Actas del IV Congreso Internacional de la SEHL. La Laguna (Tenerife), 22-25 octubre de 2003, ed. Corrales Zumbado, C.; Dorta Luis, J. et al. Madrid: Arco Libros, 2005 [2004]. p. 113-145. 